\title{
A German Innovative Technology Teaching Project in Cooperation Between (Secondary) School, State Seminar and University
}

\author{
Ulrike Salat Ph.D. \\ Alexandra Ströbele B.Sc. \\ Henrike Seidinger Dipl. Biol. \\ Stefanie Lützow Dipl. BA (FH) \\ Ursula Eschenhagen Dipl.-Ing. (FH) \\ Markus Bur am Orde M. Eng. \\ David Ankele B.Sc \\ University of Furtwangen, Germany
}

doi: 10.19044/ejes.v3no4a1 URL:http://dx.doi.org/10.19044/ejes.v3no4a1

\begin{abstract}
"Technology Initiative for NwT (Natural sciences and Technology) school courses" was an innovative teaching project in cooperation between the University of Furtwangen (HFU), the State Seminar for Didactics and Teachers Education Rottweil and the Fürstenberg Gymnasium (FG) Donaueschingen. The main objectives of this project were the development of teaching units and the implementation of advanced training for NwT-teachers in the fields of process, medical and energy engineering. The ultimate aim is to facilitate a higher level of technology teaching in NwT school courses and in consequence to have more school graduates interested in and suitable for engineering studies. Between 2012- 2015, 39 technology teaching units were published and 325 teachers took part in 18 workshops. Evaluation of the project showed that many teachers used the training material in class. The hope is that more and improved technical education in school will lead to more engineering students and therefore more engineers in Germany who can fill the current engineer's gap. The project will continue this year focusing on advanced training for teachers as well as the development of further technical and project-oriented teaching material.
\end{abstract}

Keywords: Technology teaching project, Process Engineering, Medical Engineering, Energy Engineering, HFU (Hochschule Furtwangen/ Furtwangen University) 


\section{Introduction: The innovative cooperative teaching project "Technology initiative"}

\subsection{NwT (Science and Technology) in school and the motivation for this initiative}

In 2007 / 2008 the school subject NwT was introduced into all state gymnasia in Baden-Wuerttemberg as a major science subject. Ever since, it is a four-hour core subject in classes 8-10, and in addition, as a trial, selected schools only offer two hours laboratory training per week in classes 11-12 . The basic subjects biology, physics, chemistry and geography form the scientific base and shall be integrated into the new subject NwT. The NwT teachers originally had taught these basic science subjects and now teach NwT, as specific training as a teacher for NwT was not available until 2010 / 2011. The topics in NwT are influenced by the pupils world of experience and thought and, as an integrated discipline, shall be considered from the view of all sciences and technology. Scholastic standards for NwT, available on the official website for teacher training Baden-Württemberg say "Special emphasis is placed on the experimental and project-oriented work within an action-oriented and student-centered education”. (Ministry of Education, 2016). The comprehension and realisation of the subject NwT vastly differ from school to school and from teacher to teacher. It ranges from the enjoyment of technology to the gain of complex, technical and engineering, practical and theoretical abilities. The enormous variation in the implementation of NwT partly comes from the subject's sudden introduction and the initial lack of NwT teaching material, in contrast to an abundance of material on individual subjects. The main reason most likely is the teachers' missing technical education, and hence the technology aspect can only be taught in an insufficient way.

The continuing education of teachers in NwT is primarily organized by the regional councils and the website hosts for teachers training. In the beginning, use was made of offers from single schools as well as of highly involved teachers, who expedited elaborations of lessons and made them available. In addition, there was an offer of third party training courses. These were mainly financed by Baden-Wuerttemberg, universities or/and foundations (e.g. NaT-Working-Project, KoScHT-Project, GuT-Project). This cooperation between schools and universities in the field of NwT is of high interest for universities of Applied Sciences, because today's pupils will be tomorrow's students. The school must found the interest in engineering sciences. This can be possible if teachers consider exciting, scientific, realistic and everyday life-oriented topics and teach them in a technical engineering way. The schools should make use of the technical expertise of the universities of Applied Sciences to create a win-win-situation and ultimately to arouse the pupils’ interest in engineering. 


\subsection{Aim, cooperation partners and catalogue of measures}

As the title suggests, the aim of the project was to strengthen the technological aspect in NwT lessons by knowledge transfer from the universities to the schools concerning technological topics and approaches.

A cooperation between school-university and the State Seminar for Didactics and Teacher Education was pursued to ensure that all aspects of a technological application-oriented teaching are accounted for. The University of Applied Sciences Furtwangen (HFU) acted as the applicant and the implementing institution (faculty Medical and Life Sciences on the campus Villingen-Schwenningen, in the past known as faculty mechanical engineering and process engineering). Cooperation partners were the State Seminar for Didactics and Teaching Rottweil and the Fürstenberg Gymnasium (secondary school) Donaueschingen.

The Fürstenberg Gymnasium Donaueschingen (FG), a state secondary school, founded in 1778, with currently 1200 pupils and more than 80 teachers, is the central high school for the huge catchment area of the southern Black-Forest-Baar region. (Fürstenberg-Gymnasium, 2016). The FG is famous for its scientific specification, numerous prices at school competitions such as the German youth sciences and technology contest "Jugend forscht" (the FG is the biggest "Jugend forscht" school in BadenWürttemberg since 2007). There is a long-lasting active cooperation between the FG and the HFU, as can be seen in the project "SCHULE meets HOCHSCHULE", which represents an integral part of the study and examination regulations at the HFU. In this project, students establish an experiment to a concrete question. This experiment is then introduced to pupils, who will give the final presentation.

The State Seminar for Didactics and Teaching Rottweil, founded in 1964, assumes, within the teacher training, the training for future high school teachers, meaning the education of student teachers in form of technical meetings. (Staatliches Seminar für Didaktik und Lehrerbildung, 2016). Therefore, the seminar works closely together with the training schools and high schools. The seminar itself imparts teaching methodology, school legislation and pedagogy in the most diverse areas (from math through foreign languages to natural sciences), including NwT.

The University of Applied Sciences Furtwangen (HFU), founded in 1948 in Furtwangen, with its current 6000 students from ten faculties is, as a University for Applied Sciences, very closely interlinked with the local industry and mainly educates students in the field of natural sciences. (Hochschule Furtwangen, 2016). Courses such as Molecular and Technical Medicine, Biological and Process Technology, Medical Engineering and Machine Engineering are offered at the site in Schwenningen. There are courses, in which both the engineering and scientific basis are laid. The focus 
rests on an intense practical training, to have professionally qualified graduates. Professors are only appointed, if they can prove years of industrial experiences. The laboratories of the HFU are equipped with state-of-the-art technologies. There are faculties like chemistry, biology and physics, as well as a large technical center and electrical engineering laboratory.

In order to reach the projects aim - the strengthening of the technological aspect in NwT - the following catalogue of measures was set up:

- Elaboration of lessons in the fields of process engineering, medical engineering and power engineering as well as their publication on the project's homepage (see 2.1). The decision in favor of the subjects mentioned above was made due to courses with corresponding knowhow and laboratories but also due to the fact that, especially in those fields, not enough teaching material was available.

- Implementation of advanced training courses for NwT teachers (see 2.2) in the fields of process engineering, medical engineering and power engineering. In this context, the elaborated lessons should serve as a basis.

- Evaluation of all activities at the first level (Inquiry: determining satisfaction and where required, readjustments) as well as, according to Kirkpatrick (1994), in combination of third and fourth level (transfer of knowledge into lessons / practical application)

The HFU provided technical knowledge to implement the measures, the State Seminar for Didactics and Teaching Rottweil provided the didactic and the Fürstenberg Gymnasium facilitated the transfer into the school. It was then possible to develop appropriate lessons regarding content and didactics.

In 2011, the project was presented to the Ministry of Science, Art and Culture of Baden-Württemberg at the IQF (Innovation and Quality funds) tender "cooperation models in teaching training" and was approved in the same year.

\section{Results from a three years' experience}

The project Technology Initiative was provided with $583230 €$ from IQF state funds for the entire three years' project period. Alltogether, 2,5 full-time employees worked for the project averaged over three years. They developed 39 elaborations of lessons, including 20 in the area of process engineering, 13 in the area of power engineering and six in the area of medical engineering. 18 advanced training courses were offered in all three areas throughout the entire term (see table 1). In February 2014, the first NwT congress with 171 participating teachers and student teachers took place at the 
University of Furtwangen (see table 3).

\begin{tabular}{|l|l|l|l|}
\hline \multicolumn{1}{|c|}{ Topic } & $\begin{array}{c}\text { Number of } \\
\text { lessons }\end{array}$ & $\begin{array}{c}\text { Number of advanced training } \\
\text { courses }\end{array}$ & $\begin{array}{c}\text { Number of } \\
\text { participants }\end{array}$ \\
\hline Process engineering & 20 & 9 & 173 \\
\hline Power engineering & 13 & 5 & 79 \\
\hline Medical engineering & 6 & 4 & 73 \\
\hline Total & $\mathbf{3 9}$ & $\mathbf{1 8}$ & $\mathbf{3 2 5}$ \\
\hline
\end{tabular}

Table 1: General overview of the results from the Technology Initiative for NwT lessons showing the total number of elaborated lessons, the total numbers of implemented trainings and the total number of participants (participants in different courses can be the same person).

\subsection{Elaboration of lessons}

The aim in preparing lessons was to pick up new topics for the practical and technical application of school lessons. The lessons were all structured in the same, recognizable way. They consist of an introduction with theoretical background, a list of the required materials, a development and results section, and the pupils' and teachers' pages with more detailed information and project proposals. The development and results sections deals with topics in a modular and level differentiated way and therefore offers a huge variety for individual lessons. Once a lesson was prepared and tested at the HFU, project teachers were hired who tried out the lessons in school and reworked them didactically. The elaborations are password protected and are available for download from the Technology Initiative's homepage by all those, who request a password. (Technikinitiative NwT. 2016).

\subsection{Implementation of advanced training courses for teachers}

The advanced training courses are normally one-day-events covering all focal points and pursue a standardized scheme. After the participants had been welcomed, the specialized lecture followed, which introduced the topics power engineering, medical engineering and process engineering and in general, a professor of the HFU held the lecture. Afterwards, the project team members introduced the specific teaching contents, presented the agenda of the day and divided the participants into groups. A large part of the day was spent in the laboratory implementing experimental lessons. These lessons, elaborated by the project itself (see figure 1, 2, 3), were compiled for each training in a meaningful manner and quantity. Each participant implemented an average of 2-4 lessons per training day (see table 2). The high percentage 
of the practical part was explicitly requested, as NwT shall be taught in school in an experimental way. The personal experience gained from the training enables the teacher to use it in school. The training day ended with a concluding discussing, including feedback and evaluation of the training course.

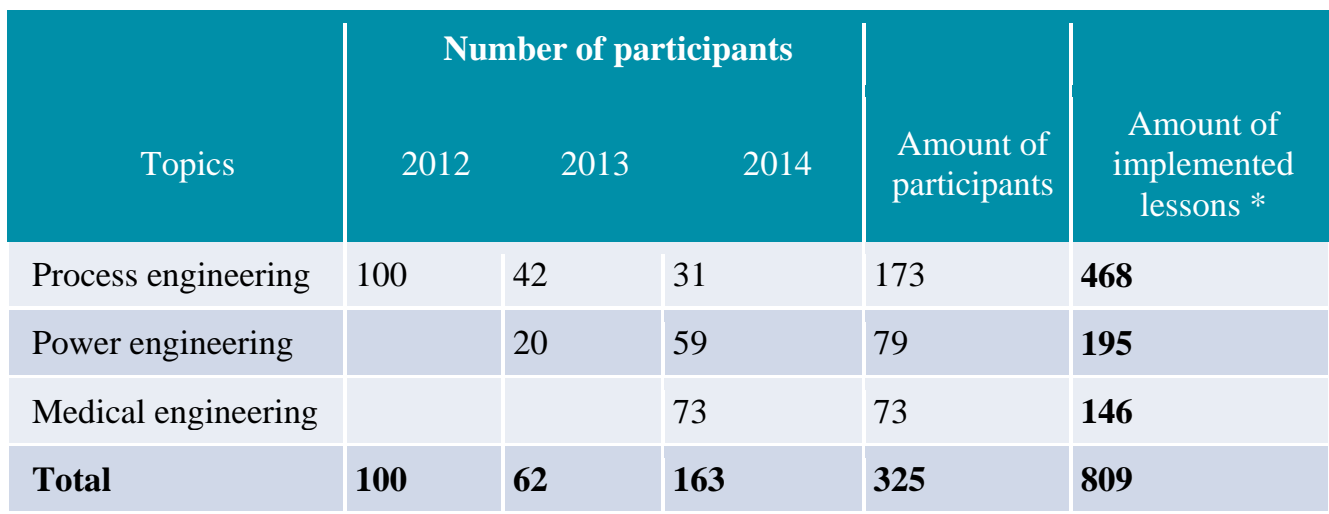

(* Usually, a participant carried out several tests per seminar.)

Table 2: Advanced training courses of the Technology Initiative. Number of advanced training courses with the amount of participants and total sum of implemented experimental units, listed thematically and chronologically.

There was great interest in the courses offered (table 2). The teachers came from all parts of Baden-Wuerttemberg. Overall, the participants represented 30\% of Baden-Wuerttemberg's high schools (112 high schools of a total of 378) Regional Council Stuttgart, Department 71. (2016, January 21). Retrieved from https://rp.badenwuerttemberg.de/Themen/Bildung/Eltern/Bildungswege/Seiten/Allgemein-bildendesGymnasium.aspx).

\subsection{First NwT Congress at the University of Furtwangen}

On 24 February 2014, the first NwT Congress was held at the University of Furtwangen including high-ranking politicians and education experts. It served as a platform for a professional exchange between all NwT contributors. Minister for education Stoch inaugurated the Congress, which was visited very frequently by approximately 200 teachers and student teachers. Prof. Dr. Nickolaus from the University of Stuttgart gave the key note lecture entitled "Effects of methodological decisions on the motivational and competence development in technical lessons". A NwT exhibition, advanced training courses in NwT and a lecture serie on different aspects of NwT accompanied the Congress (see table 3). 


\begin{tabular}{|c|c|}
\hline 8 advanced trainings / workshops & 7 lectures \\
\hline Power engineering & “Generis of NwT “ G. Stern, \\
\hline Medical engineering & “Understanding medical engineering” R. Frank \\
\hline Energy village & "Didactic model for planning and optimizing NwT \\
\hline Creative-technical 3D-workshop & P. Geiger, Dr. F. Haag , T. Kreß \\
\hline $\begin{array}{l}\text { Researching, project oriented lessons } \\
\text { based on the example „water wheel“ }\end{array}$ & $\begin{array}{l}\text { "Production engineering in NwT", } \\
\text { Prof. Dr.-Ing. M. Plank }\end{array}$ \\
\hline $\begin{array}{l}\text { Process engineering based on the } \\
\text { example of apple juice production }\end{array}$ & $\begin{array}{l}\text { "Technology for pupils and teachers", } \\
\text { Prof. Dr.-Ing. H. von Eiff }\end{array}$ \\
\hline $\begin{array}{l}\text { Sun lotion }- \text { an emulsion with } \\
\text { protection factor } \\
\text { Working with CAD based on the } \\
\text { example SketchUp }\end{array}$ & $\begin{array}{l}\text { "Escape the ivory tower - NwT projects with } \\
\text { cooperation partners outside school", } \\
\text { M. Mosbacher } \\
\text { "A didactive model for NwT lessons till course } \\
\text { level", R. Kügele }\end{array}$ \\
\hline
\end{tabular}

Table 3: Content overview of NwT Congress on 24 February 2014 at the University of Furtwangen. Very informative and inspiring presentations could be offered due to the participation of the Esslingen University of Applied Sciences, the State Seminar for Didactics and Teacher Education Rottweil / Esslingen and Freiburg, the Fürstenberg Gymnasium, the company TECVEST and the Federal Government of Bavaria.

\section{Evaluation of all activities}

\subsection{Evaluation results of the advanced training courses}

The participants evaluated all advanced training courses before (query of expectations in a-part of figures) and after (query of satisfaction in b-part of figures) the event (see figure 1, 2). These are evaluations of the first level according to Kirkpatrick (1994). The success of the event was thereby reviewed. Constructive discussions assured the appropriate adaption and advancement of the training, of the topics worked on as well as of the lessons. 1

\footnotetext{
1 Discrepancies between the overall sum of participants and the sum of following answers come off by the fact that at the beginning of the project 70 participating student teachers could not be included in the evaluation due to incomparable data sets.
} 


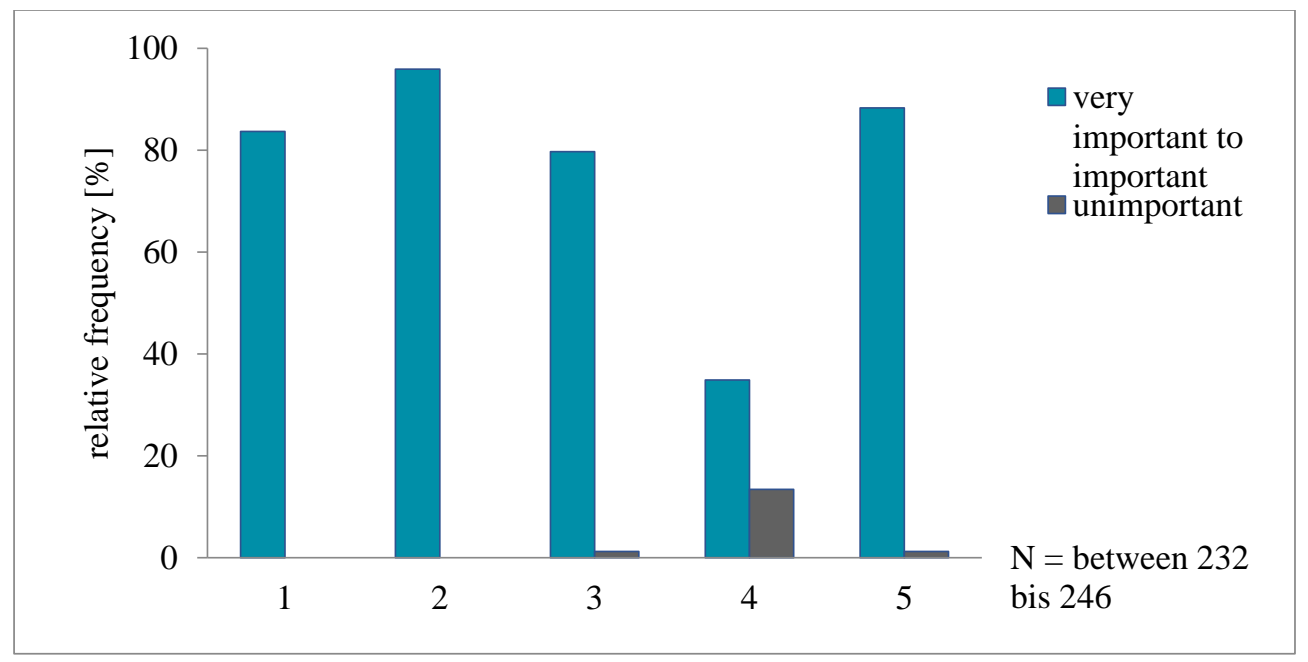

Figure 1a: Expectations on the advanced training courses. Relative frequency of the mention of the categories "very important" and "important" as well as the category "unimportant" within five possible assessment categories: 1 - professional training (201 out of 246), 2 - approaches on project oriented lessons (230 out of 240), 3 - finished material (192 out of 241), 4 - approaches on "Jugend forscht" (81 out of 232), 5 - suggestions for the transfer of technical implementations (213 out of 241). The expectations were inquired prior to the advanced training course.

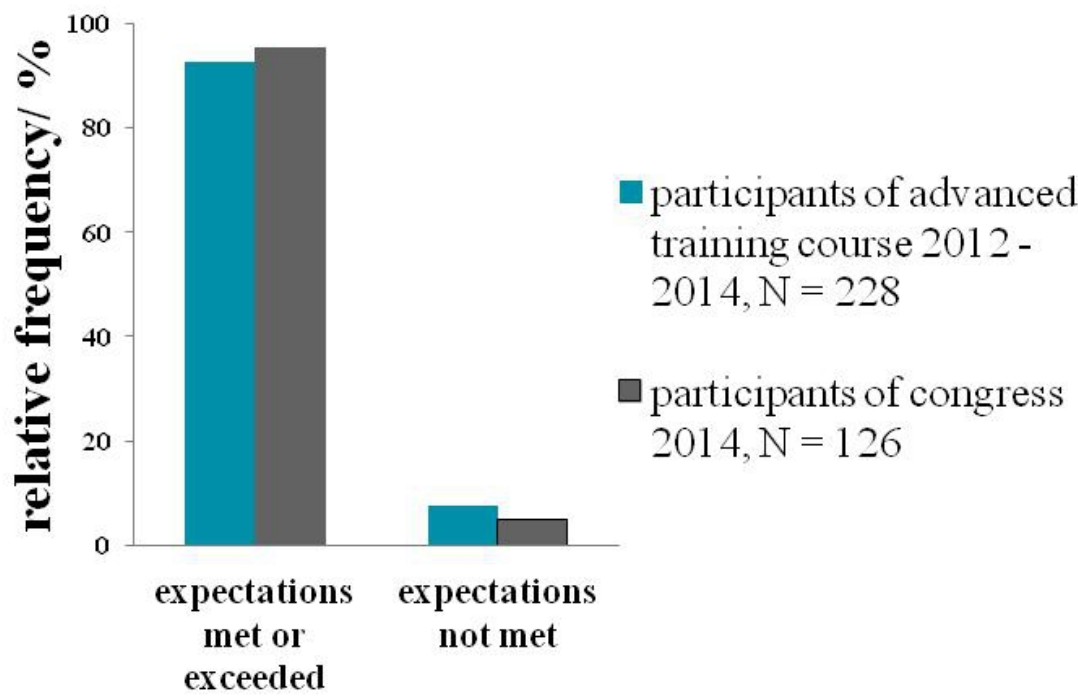

Figure 1b: Evaluation of the advanced training courses. Relative frequency of the mention of the categories "expectations exceeded" and "expectations met" (seminary: 211 out of 228, congress: 120 out of 126) as well as the category "expectations not met". The participants were inquired at the end of the course. 
Figure 1a illustrates the participants' expectations on the advanced training courses. The categories (1) professional training with 83.7\%, (2) approaches on project-oriented lessons with 95.8\%, (3) finished material with 79.9\%, (4) approaches on "Jugend forscht" with $39.9 \%$ and (5) suggestions for the transfer of technical implementations with $88.3 \%$ were evaluated as "very important" to "important". It is remarkable that the teachers evaluated the (4) approaches on "Jugend forscht" with 13.4\% (31 out of 232) as "unimportant". In contrast, figure 1b shows the participants satisfaction on all seminaries and the NwT congress. The expectations of 93 $\%$ of the participants of all seminaries were met or exceeded; the expectations of $95 \%$ of the participants of the congress were met or exceeded.

The alignment of the expectations regarding the advanced training courses and the great satisfaction allow for the conclusion that at least the categories queried, such as professional training, project-oriented work, finished material and transfer of technical knowledge could be realized and fulfilled with great success. All three focal points could fulfill the expectations to nearly the same extent. The percentual satisfaction was around $97 \%$ on the topic process engineering (72 out of 74 ), around $88 \%$ for seminaries on medical engineering (56 out of 64) and around $92 \%$ for the trainings on power engineering (69 out of 75) (data available but not listed here).

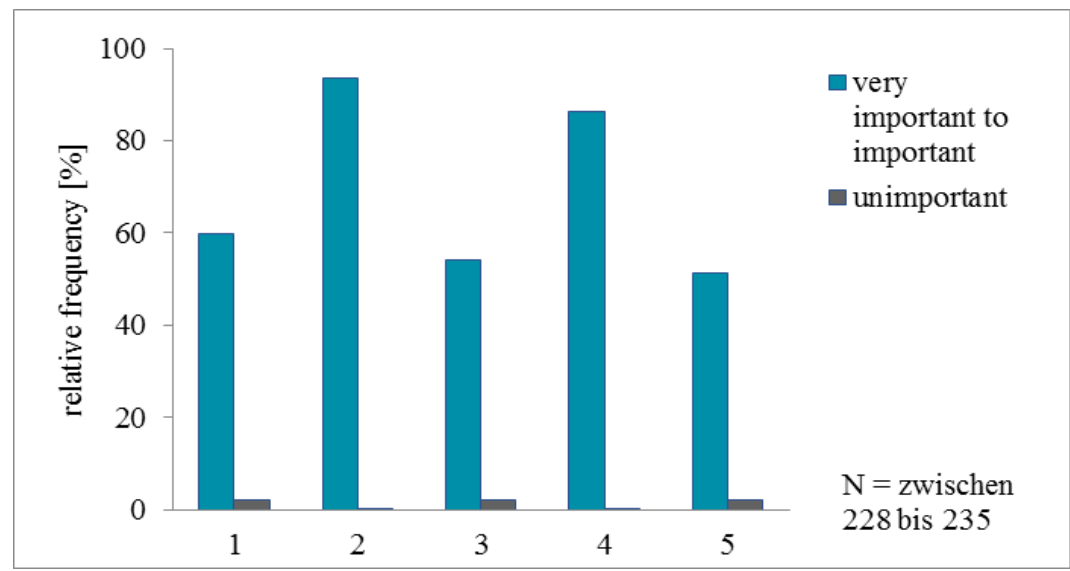

Figure 2a: Expectations on the teaching material. Relative frequency of the mention of the categories „very important“ and „important“ as well as „unimportant“ within five possible assessment categories. 1 - level differences (139 out of 232), 2 - project-oriented (220 out of 235), 3 - complete educational section (126 out of 233), 4 - educational components (201 out of 233), 5 - preferred open questioning (169 out of 228). The expectations on the teaching materials were inquired prior to the advanced training courses. 


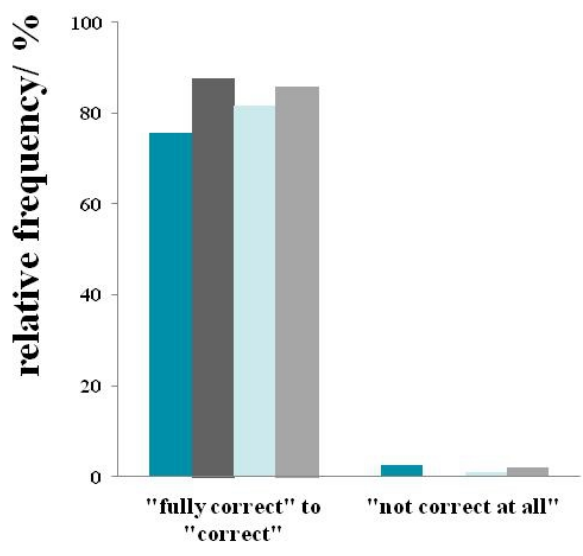

\author{
- high news value \\ - textually, technically \\ proficient \\ educational \\ implementation \\ proficient \\ aligned degree of \\ difficulty, $\mathrm{N}=$ between \\ 613 and 620
}

Figure 2b: Evaluation of the teaching material. Relative frequency of the mention of the categories "fully correct" and "correct" as well as "not correct at all" within five assessment categories. The participants were inquired at the end of the courses.

Figure 2a illustrates the participants' expectations on the available teaching material. The presence of the following criteria for the teaching material was evaluated from "very important" to "important": (1) level differences with 59.9\%, (2) project-oriented with 93.6\%, (3) complete educational section with 54\%, (4) educational components with $86,2 \%$ and (5) preferred open questioning with $51.3 \%$. Figure $2 \mathrm{~b}$ summarizes the query of the satisfaction with the Technology Initiative's teaching material. The teaching material was confirmed as "fully correct" and "correct" in regards to high news value $(75.5 \%$, 468 out of 620$)$, textually, technically proficient (87.6\%, 539 out of 615), proficient educational implementation (81.7\%, 503 out of 616) as well as aligned degree of difficulty (85.9\%, 526 out of 613). The increased number of answers is attributed to the fact that in average three lessons were carried out and evaluated by the participants in each seminar. 


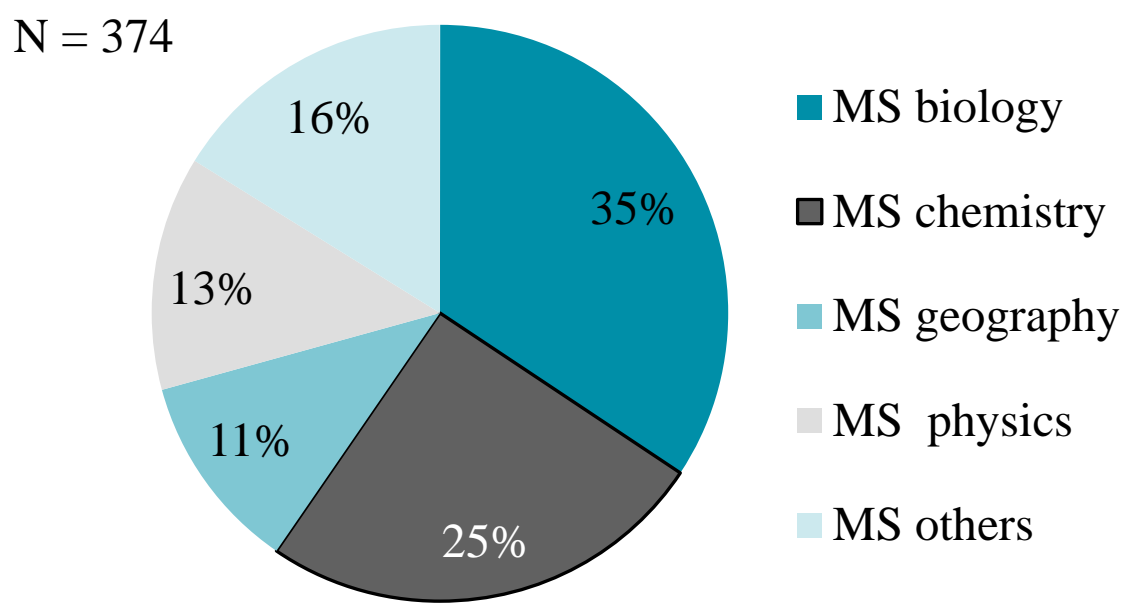

Figure 3: Subjects of the participating teachers (seminars and congress). Participants (only 243 of the 325 participants total) were asked about their qualification to teach a particular subject (MS, main subject), each teacher has the qualification to teach two, sometimes three subjects, given numbers of subjects per participant were 1-3. ( $\mathrm{N}=$ mentioned subjects $\mathrm{N}=374$ )

As a result of the given information about the participant's subjects, biology was the most frequent main subject of the participants (35\%, 129 out of 374), followed by the main subjects chemistry (25\%, 95 out of 374), physics (13\%, 49 out of 374) and geography (11\%, 40 out of 374). When interning this total result according to the focuses, a slight shift between the process engineering (PrE), medical engineering (ME) and power engineering (PE) seminaries can be seen: between $30-40 \%$ of the participants stated to have biology as their main subject. Between 23-28\% stated to have chosen physics and between $9-12 \%$ have chosen geography as their main subject (PrE N = 155, PE N = 114, ME N = 105, data available but not listed here). The following tendencies can be recognized: biologists prefer MEseminaries, whereas physicists prefer PE-seminaries.

\subsection{Evaluation results of the online survey evaluation}

In a further evaluation step, according to Kirkpatrick, the third and fourth assessment levels were interconnected (Kirkpatrick et al 1998). On the one hand, the popularity of the Technology Initiative's actions was verified, as well as the applications of knowledge gained from the advanced training courses and the usage of the project lessons (table 5 and 6). On the other 
hand, the conclusions resulting from the practical application were collected and utilized. The conclusions were the result of detailed feedback, mainly through the project managers. The evaluation took place in consequence of an online survey 28 January 2015 via homepage and a mailing campaign (involving all participants of training courses and the congress as well as additional contacts). The recovery rate of this survey was 80/350.

\begin{tabular}{|l|c|c|}
\hline Topic of lesson & $\begin{array}{c}\text { Known lessons (only lessons, on which } \\
\text { advanced training courses were } \\
\text { offered) } / \%\end{array}$ & $\begin{array}{c}\text { Known lessons (lessons where training } \\
\text { courses were offered AND lessons that } \\
\text { were only on the homepage without } \\
\text { training courses offered)/\% }\end{array}$ \\
\hline PrE & 78.9 & 57.0 \\
\hline PE & 56.2 & 47.9 \\
\hline ME & 68.7 & 62.8 \\
\hline
\end{tabular}

Table 4: Lessons' popularity, split into topics process engineering (PrE), power engineering (PE) and medical engineering (ME). The participants of all advanced training courses were inquired via online survey in January $2015(\mathrm{~N}=80 / 350) .100 \%=$ all lessons of the Technology Initiative are known.

Table 4 illustrates that 56\% (145 out of 258) of the respondents were familiar with the Technology Initiative lessons about power engineering that were offered in the seminaries. 69\% (103 out of 150) were familiar with lessons about medical engineering and 79\% (194 out of 246) were familiar with process engineering. The familiarity of all lessons, including those without further education offered, was, as expected, approximately 6-22\% lower. This leads to the conclusion that the degree of familiarity of the project's lessons can be increased through their implementation in advanced training courses. On average, the evaluating teachers were familiar with a little more than 50\% (48-63\%) of all available lessons of the Technology Initiative. It would be interesting to pursue the familiarity of the lessons over the years.

\begin{tabular}{|c|c|} 
Topic of lesson & $\begin{array}{c}\text { Numbers of all lessons used in } \\
\text { school }\end{array}$ \\
\hline PrE & 114 \\
\hline PE & 60 \\
\hline ME & 14 \\
\hline
\end{tabular}

Table 5: Application of the projects' lessons in school divided into the topics process engineering (PrE), power engineering (PE) and medical engineering (ME). The participants of all advanced training courses were inquired via an online survey in January $2015(\mathrm{~N}=80 / 350)$. 
Table 5 outlines the absolute frequency of use of the lessons, itemized by focuses. The familiarity and most of all the frequency of use reflects the fact that the training courses corresponding to the focuses were introduced yearly; that is process engineering in 2012, power engineering in 2013 and medical engineering in 2014.

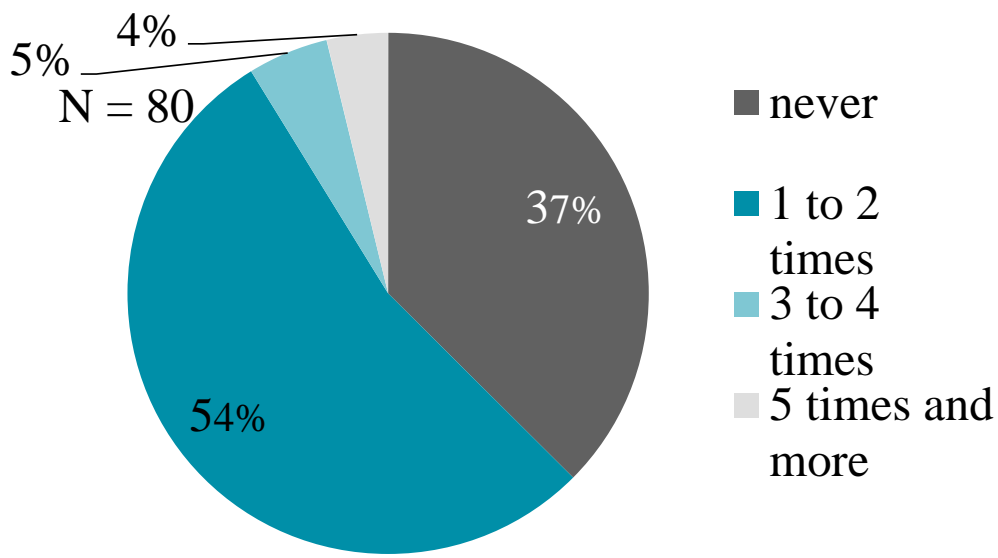

Figure 4: Frequency of use of the lesson's practical application in school. The participants of all advanced training courses were inquired via an online survey in January $2015(\mathrm{~N}=80 / 350)$.

Figure 4 illustrates that $63 \%$ (50 out of 80 ) of the respondents used lessons of the Technology Initiative for at least one time, in comparison to $37 \%$ (30 out of 80 ) who never used material of the Technology Initiative.

This high percentage of practical application in class shows above all the usability of the lessons created by the project as a valuable tool for teachers of NwT.

\section{Conclusion of the project and outlook}

The project Technology Initiative for NwT school courses started three years ago to transfer the technological knowhow from the University of Applied Sciences to schools. New, practical and significant social topics from the engineering sciences should be prepared textually and didactically for school lessons. A hitherto not existing bridge between the school, the university and the State Seminar for Didactics and Teacher Education was built to meet the high technical, didactical and application-oriented requirements.

\subsection{Conclusion of the project "Technology Initiative for NwT school courses"}

At the end of the three years funding a throughout positive result can be see. The evaluation results demonstrate that the advanced training courses as well as the elaborated teaching materials comply with the requirements of 
the teachers (see figure 1 and 2). The Technology Initiative is especially satisfied with the fact that the elaboration of the Technology Initiative covers requirements, such as "project orientation" or "level differentiation". With these results, the teaching materials and advanced training courses are in line with the present trend of the current didactic for the NwT school course, which intensely emphasizes project-oriented work.

A wide network of all NwT participants was created in these three years: due to the variety of activities offered (table 2), the NwT congress (table 3), the direct exchange with the teachers, the multiple dialogues with subject specialists, the Technology Initative's homepage (www.technikinitiative-nwt.de), the data acquisition and the maintenance of the schools and teachers - and not least by the intense exchange with the cooperation partners, the Seminar Rottweil and the Fürstenberg Gymnasium. The requested textual diversity and freedom, paired with various requirements for NwT school courses at the schools call for a broad network. This is to be able to offer diverse and profound content and material and therefore, to achieve a broad, sustainable acceptance among NwT teachers.

After almost eight years of existence, the NwT course sees itself confronted with undergoing changes. Project-oriented lesson sequences, which shall build on one another through grade levels, and the definition of concrete competencies become a focus in NwT courses.

The new education plan is valid now (from 2016 on) and is to be realized in NwT courses in 2018. It shall initiate further development of NwT courses as well as a specific didactic orientation of NwT lessons (personal correspondence with the experts on the education plan Rainer Kügele and Alexander Schäfer).

The teaching method of project-oriented lessons is not new, especially not at universities. Already at the beginning, the pedagogy of the $20^{\text {th }}$ century of John Dewey and William Heard Kilpatrick showed the way forward for projects in science lessons (Dewey and Kilpatrick, 1935). Over the next century, there were numerous adherents of this teaching method, which, above all, emphasizes the problem-solving, interdisciplinary and product-oriented character of the project's concept.

This stands in contrast to studies, which show that didactic methods (e.g. experimental teaching vs. teacher-centered teaching) barely affect the technical affinity or no general assumptions on the impact can be made. Furthermore, big differences in the results of the surveys occurred according to the subject matter, e.g. between natural sciences and technology. Nickolaus (2014) generally states that most of all the quality of the setting defines the learning success. Hattie's big meta-study revealed that the main factor for successful learning is awarded to the teacher, not to the teaching method (Hattie, 2008). According to Hattie, the big majority of new 
pedagogical approaches ("open education”, “discovery learning”, "webbased teaching") has barely any influence on the educational success. "Feedback" (in both directions) is one of the most important factors for successful lessons. Hattie states that the clarity of requirements, regular performance review, teacher-led lessons, additional offers for strong and weak pupils, problem-solving lessons, subject-specific teacher trainings etc. are central modules of successful learning. The demand on the technical lessons Hattie extracted are, like the present survey of the teachers show, still current (figure 2). Especially project-oriented, technical lessons and their didactical realization against the background of several restrictions (such as gaps in training, lack of time and gaps in equipment) will pose various, enormous challenges for NwT teachers in the future.

\subsection{Continuation of the project in 2015 and 2016 as version 2.0}

Since 2015, the project Technology Initiative for school courses, now as version 2.0, continues with financial support from the University of Furtwangen and the training institute Südwestmetall as well as funding from the chemical industry in 2016.

New measures of the follow-up project set the focus on multi-day, deepened and interrelated teacher training based on one special field (PrE, $\mathrm{ME}$ or $\mathrm{PE}$ ) as the threshold of using the lessons in class is still too high for about $1 / 3$ (37 \% see figure 4 ) of the participants. It could be lowered through theoretical and practical training courses.

The lessons and components of the advanced training courses are further on available as online versions. Not just the lessons are available as download, but also parts of the advanced training courses, in terms of blended-learning-events, are on offer on the homepage.

Another focus lies on the strengthened project orientation of the advanced training courses, which now begin with a learning circle, lasting several days, and end with a project of the teachers. The teachers are hereby supported in qualifying the pupils for a topic and on this basis to develop a project within an open questioning independently. The Technology Initiative 2.0 is therefore oriented towards the developed didactic-pedagogic concepts for NwT school courses as well as towards the new education plan, published in 2016.

A new feature of the Technology Initiative 2.0 is also to provide modules and teacher training up to classes 11-12. It will only succeed in arousing enthusiasm for engineering sciences if an integrated NwT concepts exists at a school throughout the complete schooldays. Therefore, the number of schools, which offer NwT in class 11-12 (currently $10 \%$, this corresponds to 40 high schools in Baden-Wuerttemberg) shall be significantly increased in the next few years so that a comprehensive offer is generated (Personal 
dialogue with Alexander Schäfer, regional council Stuttgart). For this purpose, appropriate teaching material needs to be developed and teachers, who are able to offer established specialized classes, need to receive further education. The aim is to contribute constructively to achieve the big longterm goal of NwT becoming an exam subject of the centralized A-level. These graduates with strong interest in engineering and a funded scientificorientated background are valuable engineering students and will fill the engineers' gap in Germany in future.

\section{References:}

Dewey, J.; Kilpatrick, W. H. (1935). Der Projekt-Plan. Grundlegung und Praxis. (üb. v. Georg Schulz u. Ernst Wirsenthal) Weimar : H. Böhlaus

Fürstenberg-Gymnasium (2016, October 20) Retrieved from http://www.fuerstenberg-gymnasium.de

Hattie, J. (2008). Visible Learning: A Synthesis of over 800 Meta-Analyses Relating to Achievement. London and New York: Routledge Taylor and Francis Group

Hochschule Furtwangen. (2016, October 20). Retrieved from http://www.hsfurtwangen.de

Kirkpatrick, D. L. (1994). Evaluating Training Programs: The Four Levels. San Francisco, CA: Berrett-Koehler Publishers Inc.

Ministry of Education. Landesbildungsserver Baden-Württemberg, Bildungspläne und Materialien. (2016, October 20). Retrieved from http://www.bildung-staerkt-

menschen.de/unterstuetzung/schularten/Gym/faecher/NwT/listing_bildungsst andards

Nickolaus, R. (2014) Differentielle Effekte methodischer Entscheidungen auf die Motivations- und Kompetenzentwicklung im Technikunterricht. Oral Presentation at NwT Congress, 24.02.14, Hochschule Furtwangen, Campus Villingen-Schwenningen

Staatliches Seminar für Didaktik und Lehrerbildung (Gymnasien) Rottweil. (2016, October 20). Retrieved from http://www.gym.seminar-rottweil.de Technikinitiative NwT. (2016, October 20). Retrieved from http://www.technikinitiative- 